\title{
Differences and Similarities on Neuronal Activities of People Being Happily and Unhappily in Love: A Functional Magnetic Resonance Imaging Study
}

\author{
Christina Stoessel $^{\mathrm{a}} \quad$ Juliane Stiller $^{\mathrm{a}}$ Stefan Bleich ${ }^{\mathrm{a}}$ e Dominikus Boensch ${ }^{\mathrm{a}} \mathrm{d}$ \\ Arnd Doerfler $^{b} \quad$ Meritxell Garcia $^{b}$ Tanja Richter-Schmidinger ${ }^{a}$ \\ Johannes Kornhuber ${ }^{a} \quad$ Clemens Forster $^{c}$ \\ Departments of a Psychiatry and Psychotherapy and ${ }^{\mathrm{b}}$ Neuroradiology, and ${ }^{\mathrm{C}}$ Institute of Physiological Studies, \\ University of Erlangen-Nuremberg, Erlangen, dDepartment of Psychiatry and Psychotherapy, Rickling, and \\ e Department of Psychiatry and Psychotherapy, $\mathrm{MHH}$, Hannover, Germany
}

\section{Key Words}

Functional magnetic resonance imaging $\cdot$ Blood oxygen level dependency $\cdot$ Romantic love $\cdot$ Emotion $\cdot$ Depression • Grief

\begin{abstract}
Background: Brain activity was studied in grief following frustrated love compared to romantic love, and it was hypothesized that unhappy lovers compared to happy lovers would have decreased brain activity in regions specific to emotional and reward circuits, such as frontal brain areas, anterior cingulate cortex (ACC), bilateral insula or posterior cingulate cortex (PCC). Methods: Twelve volunteers intensely in love and 12 volunteers recently separated from their romantic partners were scanned performing 3 runs of functional magnetic resonance imaging acquisition. Subjects viewed partner pictures versus erotic pictures during the first run of the scanning process, autobiographical pictures versus neutral pictures during the second and autobiographical texts versus neutral texts during the third run. The Passionate Love Scale (PLS) and the Beck Depression Inventory (BDI) were additionally recorded. Results: Decreased brain activity in unhappy lovers compared to happy lovers occurred in frontal areas, ACC and PCC and bilateral insula.
\end{abstract}

Unhappy lovers also revealed clinical depressive symptoms in the BDI. Conclusion: Unhappy lovers compared to happy lovers exhibited clinical depressive symptoms and reduced blood oxygen level dependency changes in a brain network which has been described as being involved in major depression. This might be a cue for the close relationship between grief and depression.

Copyright $\odot 2011$ S. Karger AG, Basel

\section{Introduction}

Romantic love is a sparsely understood part of the human mind and is regarded as a highly rewarding experience. It is characterized by focused attention to a preferred individual, intrusive, obsessive thinking about the beloved as well as emotional dependency, and it involves erotic, cognitive, emotional and behavioural components [1]. On the one hand, it can provide a feeling of ecstasy,

This work was presented in part at the DGPPN Congress, Berlin, November 21-24, 2007, and November 26-29, 2008, and at the WFSBP Congress, Paris, June 28 to July 2, 2009.

\section{KARGER}

Fax +41613061234 E-Mail karger@karger.ch www.karger.com (c) 2011 S. Karger AG, Basel

0302-282X/11/0641-0052\$38.00/0

Accessible online at:

www.karger.com/nps
Christina Stoessel, MD

Department of Psychiatry and Psychotherapy

University of Erlangen-Nuremberg

Schwabachanlage 6, DE-91054 Erlangen (Germany)

Tel. +499131853 3001, E-Mail christina.stoessel@uk-erlangen.de 
and on the other, it can cause deep suffering when frustrated.

Using functional magnetic resonance imaging (fMRI), Zeki and his group scanned the activity in the brains of subjects who were deeply in love and found an increase in the blood oxygen level dependency (BOLD) signal in the medial insula, the anterior cingulate cortex (ACC), the caudate nucleus, the ventral tegmental area, putamen, bilateral posterior hippocampus, left inferior frontal gyrus and cerebellum [2, 3]. Bartels and Zeki [2] subsequently investigated the neural correlates of both maternal and romantic love to find overlapping activations of the brain's reward system. They also found that both deactivated a common set of regions associated with negative emotions like the frontal cortex and parts of the temporal pole $[1,4]$.

Ortigue et al. [5] showed that the subliminal presentation of a beloved's name in intense love recruits subcortical pathways mediating reward, emotion and motivation systems such as the caudate nucleus, insula, parahippocampal gyri and left dorsolateral middle frontal gyrus.

Loving et al. [6] reported that relationship-focused thinking in romantic love may also change neuronal activities so that an increased secretion of cortisol occurs. Indeed, increased cortisol is suggestive of changed psychological conditions which occur in early-stage romantic love.

Grief which follows frustrated love and separation may involve depressive-type symptoms and is described to be a major risk factor for clinical depression $[7,8]$. Recent studies on grief imaged subjects by fMRI who were currently grieving the loss of a romantic relationship [7, 9] or the death of a close relative or friend. They found altered brain activity in brain regions such as the insular cortex, the ACC and the prefrontal cortex (PFC), basal ganglia and caudate nucleus. However, little is known about the effects of lover's grief on an individual's mental health.

To our knowledge, there is no study which directly compared the brain activation of both romantic love and grief via fMRI. Therefore, we performed a study which analyzed regional brain activity of subjects happy in love (happy lovers) and subjects with lover's grief (unhappy lovers). Subjects of both groups were shown partner pictures versus erotic pictures, autobiographical pictures versus neutral pictures and autobiographical texts versus neutral texts. We expected that the unhappy lovers compared to happy lovers would show decreased BOLD changes in the ACC, posterior cingulate cortex (PCC), the insular cortex and the caudate nucleus.

Neuronal Activities of People Being

Happily and Unhappily in Love

\section{Materials and Methods}

Subjects

The group of happy lovers consisted of 12 heterosexual, righthanded volunteers ( 6 men, 6 women, mean age \pm SD: $24.2 \pm 4.02$ years) who were currently intensely in love for a maximum of 6 months. The group of unhappy lovers consisted of another 12 heterosexual, right-handed volunteers ( 6 men, 6 women, mean age $\pm \mathrm{SD}: 24.08 \pm 4.5$ years) who had separated from their romantic partner within the preceding 6 months and still felt sad about the break-up. All participants were recruited by posters and via the Internet. Subjects had to be physically and neurologically healthy. Current abuse of or dependence on mentally acting substances, psychotropic medication intake, any history of psychosis, affective disorders, axis I and axis II disorders, or mental retardation led to immediate exclusion from the study. Subjects were further excluded if they were lactating or pregnant or had contraindications against MRI, such as implanted items, tattoos or claustrophobia. A total of 27 subjects who were interested to participate in this study were first screened by a detailed psychological assessment of personality and quality of their relationship. Only those subjects who fulfilled the inclusion criteria of the study were kept for the respective group. We dropped 1 female happy lover who was suspected of having an affective disorder as indicated by the psychological assessment and 2 female happy lovers because of technical problems during fMRI scanning.

Prior to the scanning session, participants completed self-report questionnaires including the passionate love scale (PLS) [10] and the Beck Depression Inventory (BDI) [11]. The PLS was used to screen the happy lovers and is described as a reliable means of quantifying romantic love [2]. Subjects with a PLS score $\geq 86$ points at the time of first assessment were included and quantified as 'passionately in love'. All of the included happy lovers were deeply and passionately in love as estimated with the PLS score (means $\pm \mathrm{SD}, 109.8 \pm 12.69$ for males and $112.4 \pm 14.76$ for females). Participants who were separated from their partners completed the BDI. BDI scores $\geq 12$ points indicate mild depressive symptoms, BDI scores $\geq 18$ points indicate clinically relevant depressive symptoms. All of the unhappy lovers showed clinically relevant depressive symptoms in the BDI (means \pm SD, $21.0 \pm 11.98$ for males and $23.0 \pm 8.60$ for females). After complete description of the study to the subjects, written informed consent was obtained. The study was approved by the local Ethics Committee.

\section{Experimental Design}

Three functional imaging runs were performed for each subject. Pictures showing the face of the beloved person (partner pictures), erotic pictures, autobiographical pictures showing a situation in the past of the relationship, photos showing a landscape and those with no object against a chessboard background were formed into a Power Point presentation which was shown to the subjects via a mirror during the MRI scanning process. Each picture was shown for $12 \mathrm{~s}$ which corresponds to 4 fMRI blocks. This results in a 4.6-min cycle for each run. For the first run, functional images were acquired with picture series of the partner pictures versus erotic pictures; during the second run, subjects viewed autobiographical pictures versus neutral pictures, and for the third run, short autobiographical texts versus neutral texts were shown. A visual control task was performed for each run showing no object against a checkerboard background. After the procedure had 


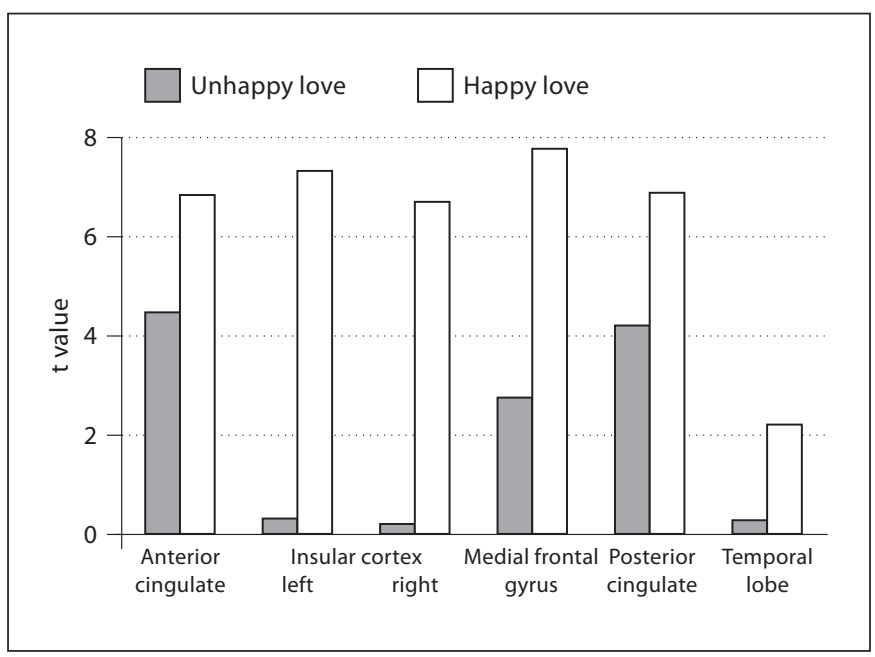

Fig. 1. Different amounts of BOLD responses in selected brain areas of unhappy and happy lovers while viewing the picture of the partner.

been explained in detail, the subjects were positioned in the scanner. The heads of the subjects were fixed by rubber pads and the ears were plugged to minimize stress induced by the scanner noise. A mirror was adjusted above the eyes to allow the subject to see the display screen outside the scanner. During the fMRI session, the subjects were instructed to view the pictures, to think of the viewed person and to relax. After completing the fMRI scan, they were asked to report how difficult it was for them to concentrate on the feelings arising while viewing the photos and if their happy or sad ruminations were similar to the feelings they experienced outside the scanner while thinking of their (ex-)partner.

\section{fMRI Data Acquisition}

Imaging was done with a Siemens Sonata 1.5-tesla MR scanner (Magnetom Sonata, Siemens Health Care AG, Erlangen, Germany). Three functional imaging runs, each consisting of 92 functional $\mathrm{T}_{2}{ }^{*}$-weighted images of the cortex, were obtained using an echo planar imaging technique consisting of 30 axial slices $(\mathrm{TR}=$ $3,000 \mathrm{~ms}, \mathrm{TE}=60 \mathrm{~ms}$, flip angle $=90^{\circ}$, slice thickness $=4 \mathrm{~mm}$, field of view $=220 \times 220 \mathrm{~mm}^{2}, 128 \times 128$ pixels). A fourth run with 42 functional images using the same slice position and acquisition parameters was acquired for the visual control task (see experimental design below). Possible head movements of the subjects were corrected online using the prospective acquisition correction of the scanner software [12]. Finally, a magnetization-prepared rapid gradient echo sequence was recorded consisting of 160 sagittal slices of $1 \mathrm{~mm}$ thickness and an in-plane resolution of $256 \times 256$ pixels (field of view $=220 \times 220 \mathrm{~mm}^{2}$ ).

\section{fMRI Data Analysis}

All postprocessing and statistical analyses of the fMRI data were performed using Brain Voyager ${ }^{\circledR}$ QX version 1.8.6 (Brain Innovations, the Netherlands, www.brainvoyager.com). Statistical analyses of the functional echo planar imaging sequences were performed after applying motion correction, slice scan time cor- rection, spatial gaussian smoothing using a 4-mm full-width-athalf-maximum in-plane Hanning window, linear detrending to remove signal drifts and temporal gaussian filtering with a time constant of $4 \mathrm{~s}$. Analysis was done with a general linear model with subjects as a random effect. Two boxcar-like predictors were used in studies 1, 2 and 3, respectively. The first predictor described the phases related to the beloved person (partner picture, landscape picture, text with memories). The second predictor described the phases related to the control situation (erotic picture, neutral picture, neutral text). Both predictor functions were convolved with a haemodynamic response function to consider delays and graded response times of the BOLD signal to the stimuli. For this a $2 \gamma$-haemodynamic response function was used (time to response to peak: $5 \mathrm{~s}$, time to undershoot peak: $15 \mathrm{~s}$ ).

The effects of predictor 1 and predictor 2 on cortical activation were analyzed separately. In addition, contrasts regarding differences in activation between the 2 predictors were calculated. All data were transformed into Talairach space for group analysis of the cortical activations.

The analysis was restricted to regions of interest (ROIs) which had previously been described as being involved in the processing of love-related experiences $[1-4,7,8,13]$ and which we expected to be involved. These ROIs were frontal brain areas, the ACC, the PCC, bilateral insular cortex, the caudate nucleus and the thalamus.

On the basis of a clustering algorithm, a cortical brain site was regarded as activated only if a minimum cluster size of $150 \mathrm{~mm}^{3}$ was reached [14]. An uncorrected p value of 0.001 corresponds to a t value of 3.3 and was regarded to be significant for detection of activated cortical areas. Only clusters which passed this threshold and which belonged to one of the ROIs defined were taken for the ongoing analysis.

The strength of the activation within subjects' ROIs was expressed by the individual t value which was obtained by a secondlevel general linear model analysis with the subject as a factor. Three t values were used to calculate Pearson's correlation coefficient between intensity of activation within an ROI and the PLS scores in subjects intensely in love.

\section{Results}

\section{PLS and BDI}

The degree of romantic love was estimated using the PLS. PLS scores in an early stage of romantic love were $109.8 \pm 12.69$ (males) and $112.4 \pm 14.76$ (females). This indicates that they were all deeply and passionately in love. Unhappy lovers were rated using the BDI. BDI scores were $21.0 \pm 11.98$ (males) and $23.0 \pm 8.60$ (females).

\section{fMRI Data}

The BOLD changes, in particular during viewing the picture of the beloved, were diminished in unhappy lovers (fig. 1). Group fMRI data are displayed in table 1 and figure 2. All subjects showed similar activations in the occipital lobe during the visual control task. 
Table 1. Regional activations specific to the pictures of the beloved compared to an erotic picture (run 1), autobiographical pictures compared to neutral pictures (run 2) and autobiographical texts compared to neutral texts (run 3) in unhappy and happy love

\begin{tabular}{|c|c|c|c|c|c|c|c|c|c|c|c|c|c|}
\hline & \multirow[t]{3}{*}{$\mathrm{BA}$} & \multicolumn{6}{|c|}{ Unhappy love } & \multicolumn{6}{|c|}{ Happy love } \\
\hline & & \multicolumn{3}{|c|}{ Talairach coordinates } & \multicolumn{3}{|c|}{$\mathrm{t}$ values } & \multicolumn{3}{|c|}{ Talairach coordinates } & \multicolumn{3}{|c|}{$\mathrm{t}$ values } \\
\hline & & $\mathrm{x}$ & $\mathrm{y}$ & $\mathrm{z}$ & $\mathrm{PP}$ & $\mathrm{EP}$ & $\mathrm{PP}>\mathrm{EP}$ & $\mathrm{x}$ & $\mathrm{y}$ & $\mathrm{z}$ & $\mathrm{PP}$ & $\mathrm{EP}$ & $\mathrm{PP}>\mathrm{EP}$ \\
\hline \multicolumn{14}{|l|}{ Run 1} \\
\hline \multirow{2}{*}{ Insula } & 13 & & & & & & & -33 & 16 & 17 & 7.31 & 4.59 & 3.64 \\
\hline & 13 & & & & & & & 34 & 22 & 9 & 6.70 & 4.01 & 3.22 \\
\hline ACC & 24 & 2 & 28 & 22 & 4.47 & 0.25 & 3.72 & 4 & 28 & 21 & 6.83 & 3.87 & 2.62 \\
\hline \multirow{2}{*}{ Superior frontal gyrus } & 8 & -17 & 48 & 41 & 3.84 & 3.25 & 0.83 & -17 & 44 & 41 & 7.06 & 2.24 & 4.26 \\
\hline & 8 & -7 & 50 & 43 & 3.54 & 2.57 & 0.85 & -9 & 50 & 22 & 6.77 & 2.39 & 3.88 \\
\hline \multirow[t]{2}{*}{ Medial frontal gyrus } & 6 & -4 & -2 & 51 & 2.75 & -0.43 & 3.64 & -4 & -4 & 51 & 7.77 & 2.45 & 3.72 \\
\hline & 9 & -5 & 47 & 17 & 4.40 & 1.72 & 3.43 & -5 & 51 & 21 & 5.84 & 2.15 & 6.80 \\
\hline \multirow[t]{3}{*}{ Inferior frontal gyrus } & 44 & -48 & 13 & 14 & 2.27 & 1.04 & 1.33 & -48 & 14 & 10 & 4.82 & 5.90 & 1.03 \\
\hline & 45 & -39 & 19 & 6 & 2.42 & 0.63 & 1.82 & -42 & 19 & 5 & 4.92 & 2.85 & 3.49 \\
\hline & 45 & 42 & 39 & 8 & 3.13 & 0.05 & 2.72 & 50 & 27 & 2 & 4.35 & 5.02 & -0.59 \\
\hline Middle frontal gyrus & 9 & -38 & 46 & 27 & 1.42 & 2.06 & 0.07 & -38 & 37 & 26 & 5.10 & 7.36 & -0.36 \\
\hline \multirow[t]{2}{*}{ PCC } & 30 & -13 & -50 & 26 & 4.22 & 0.30 & 3.25 & -12 & -54 & 19 & 6.88 & 3.48 & 3.01 \\
\hline & 31 & -5 & -53 & 16 & 4.46 & -0.41 & 4.29 & -3 & -55 & 23 & 5.58 & 2.97 & 2.31 \\
\hline Caudate nucleus & & 12 & 15 & 11 & 4.45 & 0.84 & 3.19 & -6 & 0 & 17 & 3.35 & 4.83 & -1.31 \\
\hline Precuneus & 7 & 25 & -66 & 28 & 5.12 & 3.50 & 1.43 & 26 & -64 & 27 & 5.80 & 4.19 & 1.43 \\
\hline Temporal cortex & & 49 & -61 & 9 & 0.30 & 2.52 & -3.41 & -55 & -29 & 8 & 2.21 & 6.37 & -2.56 \\
\hline Run 2 & & $\mathrm{x}$ & $\mathrm{y}$ & $\mathrm{z}$ & $\mathrm{AP}$ & NP & $\mathrm{AP}>\mathrm{NP}$ & $\mathrm{x}$ & $\mathrm{y}$ & $\mathrm{z}$ & $\mathrm{AP}$ & NP & $\mathrm{AP}>\mathrm{NP}$ \\
\hline \multirow[t]{2}{*}{ Insula } & 13 & -31 & 22 & 0 & 5.49 & 1.17 & 3.02 & -31 & 22 & 10 & 5.64 & 3.92 & 1.52 \\
\hline & 13 & 29 & 32 & 19 & 5.20 & 1.71 & 1.16 & 30 & 19 & 17 & 5.94 & 2.44 & 3.09 \\
\hline \multirow[t]{2}{*}{$\overline{\mathrm{ACC}}$} & 24 & 2 & 3 & 41 & 4.35 & 1.45 & 2.60 & 4 & 5 & 41 & 4.79 & 2.68 & 1.86 \\
\hline & 32 & -7 & 20 & 29 & 3.31 & -2.23 & 4.52 & -8 & 15 & 30 & 5.36 & 2.62 & 2.74 \\
\hline \multirow[t]{2}{*}{ Superior frontal gyrus } & 6 & -14 & -3 & 67 & 4.59 & -0.26 & 5.07 & -14 & -3 & 67 & 2.68 & 1.87 & 1.73 \\
\hline & 6 & -22 & 31 & 54 & 2.19 & -0.28 & 2.07 & -22 & 27 & 54 & 8.68 & 0.24 & 6.46 \\
\hline \multirow[t]{2}{*}{ Medial frontal gyrus } & 8 & 6 & 49 & 41 & 4.60 & 0.65 & 3.34 & 8 & 49 & 39 & 4.04 & 1.72 & 4.13 \\
\hline & 10 & 34 & 54 & 5 & 1.48 & 0.43 & 0.29 & 34 & 54 & 5 & 5.05 & 2.46 & 2.29 \\
\hline Inferior frontal gyrus & 47 & -42 & 22 & 10 & 6.10 & 2.56 & 1.61 & -37 & 20 & -8 & 6.21 & 1.54 & 4.13 \\
\hline & 9 & 54 & 19 & 25 & 4.45 & 2.31 & 1.64 & 54 & 19 & 25 & 3.92 & 1.82 & 1.57 \\
\hline PCC & 23 & -7 & -54 & 16 & 6.48 & -1.11 & 6.82 & -7 & -50 & 13 & 6.60 & -1.73 & 7.35 \\
\hline Precuneus & & -10 & -65 & 48 & 4.00 & -0.79 & 4.56 & -10 & -75 & 47 & 2.94 & -3.37 & 6.19 \\
\hline Parahippocampal gyrus & 35 & 24 & -28 & -11 & 6.26 & 0.56 & 7.17 & 30 & -28 & -13 & 8.80 & 3.78 & 3.86 \\
\hline & 36 & -24 & -37 & -12 & 7.93 & 3.10 & 4.34 & -26 & -31 & -13 & 8.82 & 3.01 & 5.13 \\
\hline Run 3 & & $\mathrm{x}$ & $\mathrm{y}$ & $\mathrm{z}$ & AT & NT & $\mathrm{AT}>\mathrm{NT}$ & $\mathrm{x}$ & y & $\mathrm{z}$ & AT & NT & $\mathrm{AT}>\mathrm{NT}$ \\
\hline Insula & 13 & -34 & 17 & 21 & 5.01 & 1.01 & 3.60 & -38 & 11 & 19 & 8.58 & 5.53 & 2.69 \\
\hline & & 40 & 9 & 20 & 4.65 & 3.63 & 0.93 & 42 & 1 & 19 & 6.29 & 2.84 & 3.05 \\
\hline$\overline{\mathrm{ACC}}$ & 32 & -7 & 36 & 13 & 3.96 & -2.43 & 5.74 & -2 & 34 & 14 & 6.49 & -3.98 & 9.27 \\
\hline & 32 & -2 & 23 & 33 & 6.39 & -4.20 & 9.51 & -4 & 16 & 36 & 8.36 & -0.61 & 7.94 \\
\hline Superior frontal gyrus & 10 & -29 & 50 & 27 & 4.00 & -4.31 & 7.50 & -25 & 46 & 21 & 5.46 & -3.37 & 8.42 \\
\hline Medial frontal gyrus & 8 & & & & & & & -7 & 46 & 41 & 5.97 & 0.06 & 5.23 \\
\hline & 9 & 9 & 34 & 27 & -1.05 & -2.56 & 1.36 & 14 & 35 & 24 & 5.08 & 2.20 & 2.54 \\
\hline & 9 & -2 & 44 & 20 & 3.05 & -4.78 & 7.03 & 1 & 48 & 19 & 7.98 & -3.12 & 9.80 \\
\hline Inferior frontal gyrus & 45 & -39 & 19 & 14 & 4.58 & 1.30 & 2.96 & -41 & 18 & 13 & 7.27 & 4.08 & 2.81 \\
\hline PCC & 29 & -11 & -49 & 12 & 3.73 & -2.92 & 5.62 & -11 & -49 & 12 & 5.19 & -0.53 & 3.45 \\
\hline Parahippocampal gyrus & 37 & -35 & -45 & -9 & 5.67 & 3.99 & 1.51 & -33 & -36 & -10 & 7.59 & 1.47 & 5.42 \\
\hline & 7 & 28 & -63 & 28 & 5.18 & 3.94 & 1.11 & 29 & -65 & 34 & 6.45 & 4.67 & 1.57 \\
\hline Precuneus & 31 & -22 & -68 & 35 & 5.52 & 2.05 & 3.12 & -22 & -68 & 35 & 7.16 & 4.41 & 2.42 \\
\hline & 7 & 21 & -72 & 34 & 4.35 & 1.45 & 2.60 & 21 & -72 & 34 & 7.84 & 2.46 & 4.75 \\
\hline
\end{tabular}

$\mathrm{t}$ values are given separately for activation while viewing: the partner picture (PP) and the erotic picture (EP) (run 1), the autobiographical picture (AP) and the neutral picture (NP) (run 2) or the autobiographical text (AT) and the neutral text (NT) (run 3) and for the contrast. Talairach coordinates, Brodmann's area (BA) and t values are displayed for local maxima. $\mathrm{p}<0.001$ uncorrected corresponds to a $t$ value of 3.3 . 


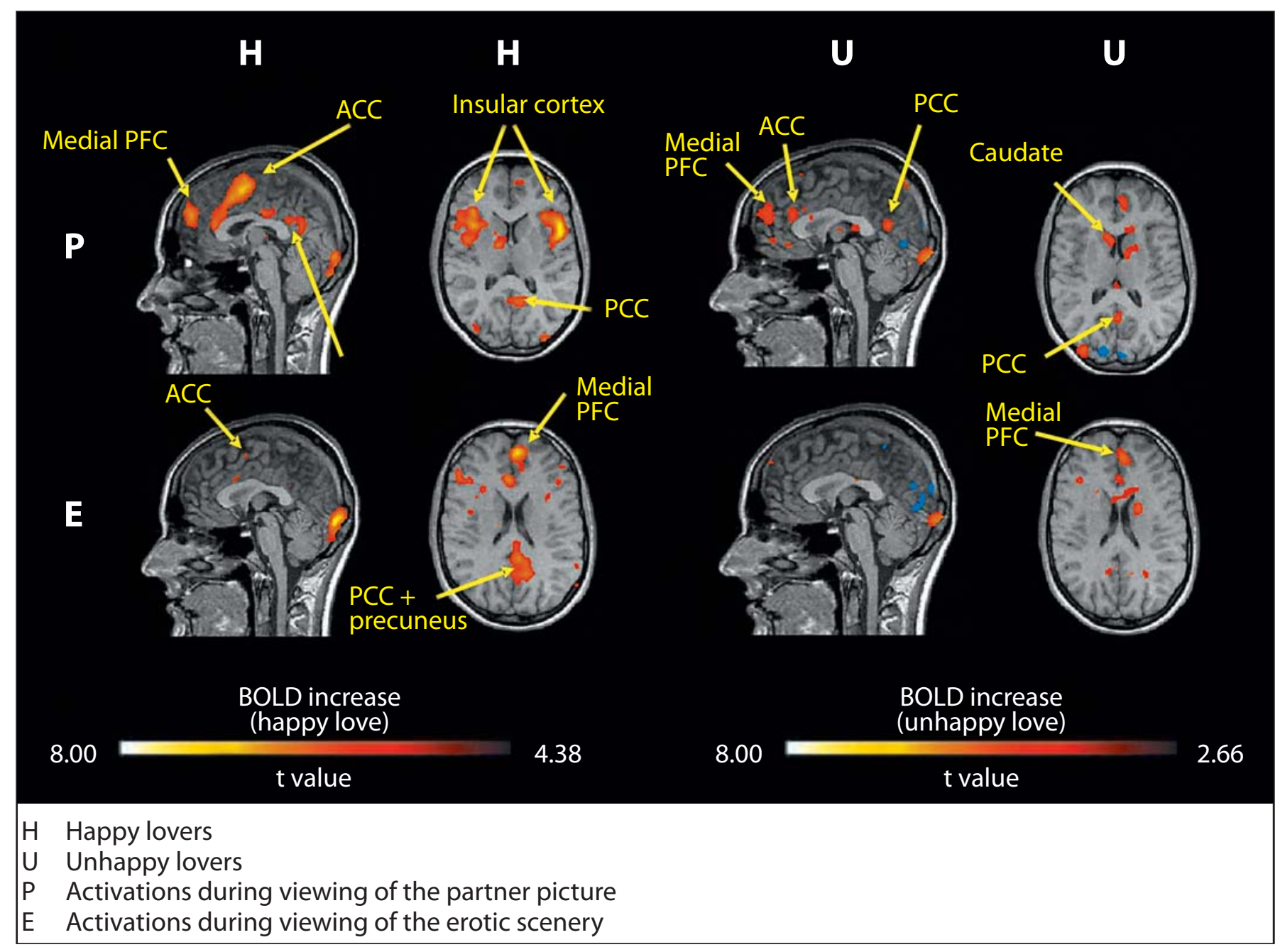

Fig. 2. Activated brain regions in happy and unhappy lovers while viewing partner pictures and erotic pictures. Regions that are more active while viewing the partner picture are marked with the red-to-yellow scale. The axial slices are located at z-level 12 (row P) and z-level 17 (row E) according to the Talairach space.

Run 1 (Changes in Regional Activity Specific to the Pictures of the Beloved Compared to an Erotic Picture) In unhappy lovers, significant BOLD increases were found in the left medial frontal gyrus (Brodman area, BA, 9), the right caudate nucleus, the right superior parietal cortex (precuneus), in the ACC (BA 24) and the PCC (BA 31) only while viewing the picture of the beloved. Contrast analyses revealed that the BOLD increases in both cingulate areas were higher while viewing the picture of the beloved than while viewing the control picture (erotic scene).

In happy love, additional regions with increased activation were observed in frontal areas such as the left superior and inferior frontal gyrus, the PCC (BA 31), the cingulate gyrus (BA 32), the left superior parietal cortex (precuneus) and bilateral insula while viewing the picture of the beloved. No brain region was found with higher BOLD increases while viewing the erotic picture in happy and unhappy love. Happy lovers showed higher BOLD increases while viewing the erotic picture than unhappy lovers mainly in frontal areas and the caudate nucleus.

Run 2 (Regional Activations Specific to

Autobiographical Pictures Compared to Neutral

Pictures) and Run 3 (Regional Activations Specific to

Autobiographical Texts Compared to Neutral Texts)

In unhappy lovers, significant BOLD increases were found mainly while viewing the scenery or reading the 


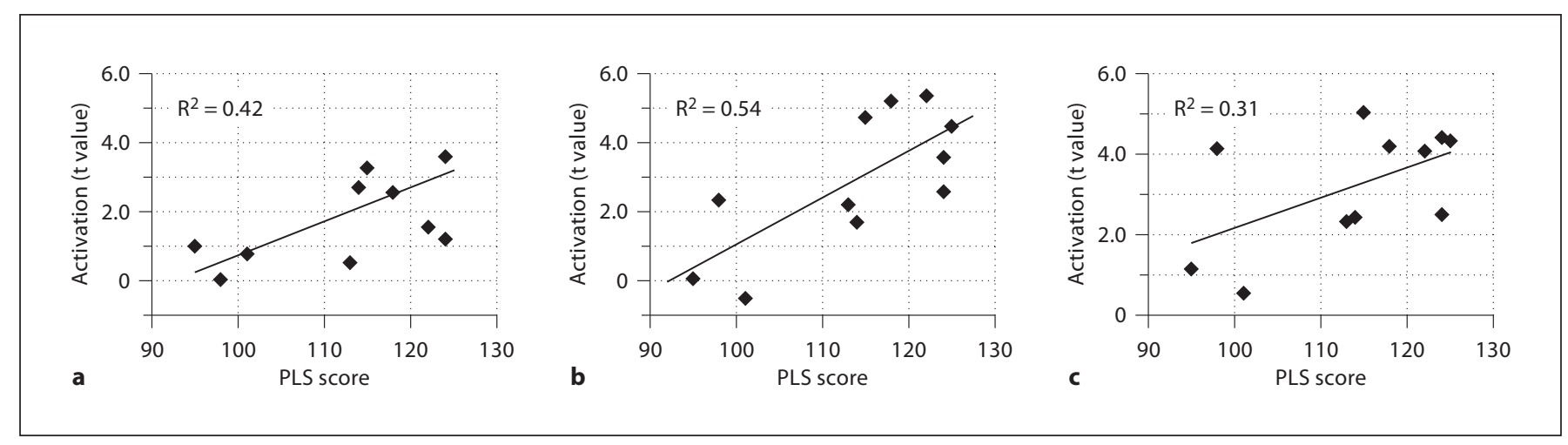

Fig. 3. Correlation between brain activity while viewing the partner picture and PLS score in 3 brain regions. The plot shows the correlations between the scores of the PLS and the BOLD increases in the respective region during viewing the partner picture. Activation is expressed by the $t$ value of the single-subject analy- sis. The Talairach coordinates given below are those of the centre of gravity of the activated region as obtained by the group analysis. a Right ACC $(4,28,21)$. b Left insular cortex $(-33,16,17)$. c Left medial frontal gyrus $(-4,-4,51)$. text regarding memories of the beloved. The affected brain areas were located in frontal areas, mainly on the left side, the ACC during the second and third run as well as the PCC and the insular cortex only during the second run. There were areas in the anterior and posterior cingulate cortex which showed reduced BOLD changes during the control task (neutral photo or text) so that the contrast analysis revealed a significant difference between the two conditions. In the group of happy lovers, a similar activation pattern was found, but in most areas the respective $t$ values were higher than those of grieving subjects, especially regarding the contrast analysis (table 1). There were also additional activations in the second run only in the left superior frontal gyrus and during the third run in all other ROIs. Activations were found in parahippocampal brain areas in both groups.

\section{Post hoc Correlation Analysis}

Focusing on the partner/erotic picture contrast, we conducted a between-subject random effects analysis correlating the degree of the BOLD response and the participant's scores on the PLS (for happy lovers) or BDI (for unhappy lovers). As shown in figure 3, PLS scores had highly positive correlations with activations in the left medial frontal gyrus (BA 6; $r=0.556, t=7.77$ ), the ACC (BA 24; $\mathrm{r}=0.563, \mathrm{t}=6.83)$ and left insular cortex $(\mathrm{r}=$ $0.735, t=7.31$ ). No clusters showed a statistically significant correlation between a subject's BDI score and brain activity in unhappy lovers.

\section{Discussion}

In our study, emotions were induced by distinct methods including photographs of the beloved as well as personalized words known to be effective in eliciting feelings of intense romantic love $[15,16]$.

As hypothesized, we found that unhappy lovers compared to happy lovers showed reduced BOLD changes in regions specific to emotional and reward circuits, such as frontal brain areas, ACC, insula, PCC, precuneus and the caudate nucleus. These brain areas also play a role across multiple individual positive and negative emotions, such as happiness, sadness, disgust as well as romantic love and grief.

\section{Activations in Happy and Unhappy Love}

In our study, mood provocation in unhappy lovers resulted in significantly reduced BOLD signals. More specifically, they were remarkably diminished in the frontal areas, the insular cortex and all areas of the cingulate cortex. The most intense response in unhappy lovers with prominent differences in activation patterns during viewing of the partner picture could be found during the first run (partner picture vs. erotic picture) and the third run (partner text vs. neutral text). No significant activation occurred in limbic regions during the first run in unhappy lovers. Consistently with our findings, a recent study on grief reports decreased activations in the ACC, $\mathrm{PFC}$ and the insula [7]. Similarly to our results, functional imaging studies on depression mainly report decreased ACC/medial PFC and dorsolateral PFC activity. 
The activity of most brain areas may be modulated by projections from limbic or paralimbic regions, resulting in variable involvement in both positive and negative emotions [9, 17-20].

The inconsistent findings across brain imaging studies may be attributed to the differences in provocation method, technical issues of image acquisition, data analysis and study design.

\section{Insula and $A C C$}

The most prominent findings in our study were the reduced BOLD changes in the insula and the ACC in unhappy lovers compared to the happy lovers. The insula can be activated by both positive and negative stimuli. It showed altered activation in depression and is thought to mediate the pleasant feelings of emotive states $[21,22]$. It has been shown that the insula is involved in both maternal and romantic love and seems to be commonly activated in caring relationships. The insular cortex and the ACC are important in the regulation of homeostasis [2325], play a role in interoceptive (somatic and visceral) attention and may participate as an alarm centre for homeostatic changes. Distressing cognitions may result in homeostatic changes that lead to changes in the cerebral blood flow. In agreement with this, the unhappy lovers show reduced cerebral blood flow due to decreased visceral blood flow. Furthermore, it could be that the absence of activation is due to the absence of autonomic responses during emotional experience. The insula and the ACC are involved in the regulation of both cognitive and emotional processing and are closely interconnected with other brain regions of emotional processing [26-28]. Consistently with our findings in unhappy lovers, PET studies report about hypometabolism or hypoperfusion in the subgenual anterior cingulate cortex in patients with clinical depression [29-31]. Inconsistently, sadness induction studies and other depression studies report increased activation of cingulate cortex areas [25,32].

\section{Posterior Cingulate Cortex}

Happy lovers had higher activations compared to the unhappy lovers in the PCC. This region has strong reciprocal connections with the parahippocampal and entorhinal cortices, and its activation is associated with the retrieval of autobiographical memories [33]. Lesions of the left PCC can lead to retrograde amnesia for personal events. Furthermore, it is connected to regions engaged in emotional processing, such as the anterior cingulate and the orbitofrontal cortices [8].

\section{Prefrontal Cortex}

The medial PFC is described as having a general role in emotional and memory processing and seems to be activated by various methods of inducing positive or negative emotions [16, 19, 20, 25, 34]. Consistently with our findings, a recent study on grief caused by separation from a romantic partner reports decreased brain activity in regions of the PFC [7]. Various sadness induction studies reported increased [16, 20, 34] as well as decreased [35] brain activity in the PFC both in healthy and depressed subjects. Consistently with our results, areas of the dorsolateral PFC show decreased cerebral blood flow and metabolism in the depressed phase of major depressive disease, compared to the remitted phase and during experimentally induced sadness in healthy subjects $[18,21,30]$.

\section{Caudate Nucleus}

The caudate nucleus is one of the most described regions related to reward and various emotions, like sexual arousal or happiness-induced recall. It seems to play a role in reward detection and expectation [25, 36, 37]. In our study, caudate activation in happy lovers occurred only while viewing the erotic picture which is in contrast to the unhappy lovers where caudate activation occurred only while viewing the partner picture. Caudate activation may reflect the activation of motor planning related to the feeling of 'being drawn toward' the beloved person $[2,8]$.

\section{Other Brain Areas: Hippocampus/Parahippocampus and Precuneus}

Activations of the parahippocampus were found during presentation of the photos or texts, respectively, with emotional/autobiographical content (runs 2/3). These regions are also involved in the retrieval of memories with emotional content [38]. It has been described that there are connections between the PFC, amygdala and basal ganglia forming a neural circuit for mood regulation [39].

Activations in the precuneus were consistent findings through all stimuli used in our study. However, little is reported about the function of this area. It may be involved in the conscious recall of memory-related imagery [40].

\section{Love and Reward}

Several studies suggest that early-stage romantic love is influenced by reward regions that are associated with reward processing $[3,15]$ such as the insula, ACC, PFC and caudate nucleus [2-4]. These regions may play a role in the experience of gains and losses. In humans, motivating rewards may also take a variety of more abstract 
forms, for example motivation by social reinforcers. Aharon et al. [41] suggested that reward value associated with a stimulus involves the individual's past experience with the stimulus. They found that beautiful female faces were rewarding without reference to a specific deficit state [41]. Happy lovers in our study experienced the perception of the face of the beloved person as pleasant and rewarding. For unhappy lovers, viewing the picture of the lost person will not evoke such pleasant and rewarding feelings which may result in diminished responses, including reduced BOLD changes in the brain regions discussed above. This is consistent with findings of McFarland and Klein [42], who reported diminished emotional reactivity in depressed individuals due to anticipated reward. O'Connor et al. [13] reported on neural reward activity which may interfere with adapting to the loss in the present. However, there is evidence for a dysfunction of the dopaminergic system in depression and for blunted response to reward signals [43]. The reward system can be suppressed by frustrating distant rewards [44]. When such suppression is extensive and persists long enough, the resulting clinical picture is that of depression, which is consistent with our findings of clinical depressive symptoms in the BDI.

\section{Love and Sexual Arousal}

During run 1, activations induced by viewing the partner picture were found which overlapped with those by viewing the erotic picture. We suggest that the cortical networks responding to sexual arousal are integrated in the emotion of being in love.

There were some limitations in the present study. We imaged women and men. There may be gender differences in the brain correlates of romantic love and grief [7]. Differences were reported in regional cerebral blood flow during different emotional states. Women show more activation in limbic and paralimbic areas during sadness and are thought to be more emotionally expres- sive. Furthermore, they seem to be more vulnerable to depressive symptoms than men [9]. Sample size, varying range of time from the beginning of the relationship, or the time of break-up and stage of grief, respectively, may influence the intensity of BOLD responses. Moreover, romantic love is a complex feeling involving erotic, cognitive, emotional and behavioural components. Grief caused by separation can also evoke a whole range of intense feelings, such as sadness, anger, hurt, fear, loneliness and confusion. Thus, brain activations may not be specific to romantic love or grief but also to other related emotions.

In conclusion, we have demonstrated that hypothesized brain regions showed reduced BOLD changes in unhappy lovers compared to happy lovers. Our study showed that grief caused by separation and frustrated love and depression have a lot in common regarding the changes in brain activation, and this gives further information in determining the effects of lover's grief on an individual's mental health. fMRI seems to be an applicable method to show individual BOLD changes due to different emotional and mood states and might be a suitable tool for clinical use in showing treatment effects in pharmacopsychiatric therapy. Further studies are needed to clarify the relationship between depressive-type symptoms due to lover's grief or caused by depression with respect to therapy and treatment.

\section{Acknowledgments}

The authors thank Joachim Demling for administrative support, Philipp Schlechtweg for assistance with MRI scanning and Verena Vierow for support with the ROI analysis.

\section{Disclosure Statement}

None of the authors has a financial or personal conflict of interest.

\section{References}

1 Zeki S: The neurobiology of love. FEBS Lett 2007;581:2575-2579.

2 Bartels A, Zeki S: The neural basis of romantic love. Neuroreport 2000;11:3829-3834.

3 Aron A, Fisher H, Mashek DJ, Strong G, Li H, Brown LL: Reward, motivation, and emotion systems associated with early-stage intense romantic love. J Neurophysiol 2005;94: 327-337.
4 Bartels A, Zeki S: The neural correlates of maternal and romantic love. Neuroimage 2004;21:1155-1166.

5 Ortigue S, Bianchi-Demicheli F, Hamilton AF, Grafton ST: The neural basis of love as a subliminal prime: an event-related functional magnetic resonance imaging study. J Cogn Neurosci 2007;19:1218-1230.
6 Loving TJ, Crockett EE, Paxson AA: Passionate love and relationship thinkers: experimental evidence for acute cortisol elevations in women. Psychoneuroendocrinology 2009;34:939-946.

7 Najib A, Lorberbaum JP, Kose S, Bohning DE, George MS: Regional brain activity in women grieving a romantic relationship breakup. Am J Psychiatry 2004;161:22452256. 
8 Gundel H, O’Connor MF, Littrell L, Fort C, Lane RD: Functional neuroanatomy of grief: an fMRI study. Am J Psychiatry 2003;160: 1946-1953.

9 George MS, Ketter TA, Parekh PI, Horwitz B, Herscovitch P, Post RM: Brain activity during transient sadness and happiness in healthy women. Am J Psychiatry 1995;152: 341-351.

10 Hatfield E, Sprecher S: Measuring passionate love in intimate relationships. J Adolesc 1986;9:383-410.

11 Hamilton M: A rating scale for depression. J Neurol Neurosurg Psychiatry 1960;23:5662.

12 Thesen S, Heid O, Mueller E, Schad LR: Prospective acquisition correction for head motion with image-based tracking for real-time fMRI. Magn Reson Med 2000;44:457-465.

13 O'Connor MF, Wellisch DK, Stanton AL, Eisenberger NI, Irwin MR, Lieberman MD: Craving love? Enduring grief activates brain's reward center. Neuroimage 2008;42: 969-972.

14 Ringler R, Greiner M, Kohlloeffel L, Handwerker HO, Forster C: BOLD effects in different areas of the cerebral cortex during painful mechanical stimulation. Pain 2003; 105:445-453.

15 Fisher H, Aron A, Brown LL: Romantic love: an fMRI study of a neural mechanism for mate choice. J Comp Neurol 2005;493:5862.

16 Teasdale JD, Howard RJ, Cox SG, Ha Y, Brammer MJ, Williams SC, Checkley SA: Functional MRI study of the cognitive generation of affect. Am J Psychiatry 1999;156: 209-215.

17 Liotti M, Mayberg HS, Brannan SK, McGinnis S, Jerabek P, Fox PT: Differential limbiccortical correlates of sadness and anxiety in healthy subjects: implications for affective disorders. Biol Psychiatry 2000;48:30-42.

18 Mayberg HS, Liotti M, Brannan SK, McGinnis S, Mahurin RK, Jerabek PA, Silva JA, Tekell JL, Martin CC, Lancaster JL, Fox PT: Reciprocal limbic-cortical function and negative mood: converging PET findings in depression and normal sadness. Am J Psychiatry 1999; $156: 675-682$.

19 Beauregard M, Leroux JM, Bergman S, Arzoumanian Y, Beaudoin G, Bourgouin P, Stip $\mathrm{E}$ : The functional neuroanatomy of major depression: an fMRI study using an emotional activation paradigm. Neuroreport 1998;9:3253-3258.
20 Lane RD, Reiman EM, Ahern GL, Schwartz GE, Davidson RJ: Neuroanatomical correlates of happiness, sadness, and disgust. Am J Psychiatry 1997;154:926-933.

21 Drevets WC: Neuroimaging studies of mood disorders. Biol Psychiatry 2000;48:813-829.

22 Damasio AR, Grabowski TJ, Bechara A, Damasio H, Ponto LL, Parvizi J, Hichwa RD: Subcortical and cortical brain activity during the feeling of self-generated emotions. Nat Neurosci 2000;3:1049-1056.

23 Craig AD: Human feelings: why are some more aware than others? Trends Cogn Sci 2004:8:239-241.

24 Critchley HD, Wiens S, Rotshtein P, Ohman A, Dolan RJ: Neural systems supporting interoceptive awareness. Nat Neurosci 2004; 7 189-195.

25 Phan KL, Wager T, Taylor SF, Liberzon I: Functional neuroanatomy of emotion: a meta-analysis of emotion activation studies in PET and fMRI. Neuroimage 2002;16:331348.

26 Bush G, Luu P, Posner MI: Cognitive and emotional influences in anterior cingulate cortex. Trends Cogn Sci 2000;4:215-222.

27 Devinsky O, Morrell MJ, Vogt BA: Contributions of anterior cingulate cortex to behaviour. Brain 1995;118:279-306.

28 Petrides M, Pandya DN: Dorsolateral prefrontal cortex: comparative cytoarchitectonic analysis in the human and the macaque brain and corticocortical connection patterns. Eur J Neurosci 1999;11:1011-1036.

29 Mayberg HS, Brannan SK, Tekell JL, Silva JA, Mahurin RK, McGinnis S, Jerabek PA: Regional metabolic effects of fluoxetine in major depression: serial changes and relationship to clinical response. Biol Psychiatry 2000;48:830-843.

30 Bench CJ, Frackowiak RS, Dolan RJ: Changes in regional cerebral blood flow on recovery from depression. Psychol Med 1995;25: 247-261.

31 Brody AL, Saxena S, Silverman DH, Alborzian S, Fairbanks LA, Phelps ME, Huang SC, Wu HM, Maidment K, Baxter LR Jr: Brain metabolic changes in major depressive disorder from pre- to post-treatment with paroxetine. Psychiatry Res 1999;91:127-139.

32 Drevets WC, Price JL, Simpson JR Jr, Todd RD, Reich T, Vannier M, Raichle ME: Subgenual prefrontal cortex abnormalities in mood disorders. Nature 1997;386:824-827.

33 Maddock RJ, Garrett AS, Buonocore MH: Remembering familiar people: the posterior cingulate cortex and autobiographical memory retrieval. Neuroscience 2001;104:667676.
34 Reiman EM, Lane RD, Ahern GL, Schwartz GE, Davidson RJ, Friston KJ, Yun LS, Chen K: Neuroanatomical correlates of externally and internally generated human emotion. Am J Psychiatry 1997;154:918-925.

35 Liotti M, Mayberg HS, McGinnis S, Brannan SL, Jerabek P: Unmasking disease-specific cerebral blood flow abnormalities: mood challenge in patients with remitted unipolar depression. Am J Psychiatry 2002;159:18301840.

36 O’Doherty JP: Reward representations and reward-related learning in the human brain: insights from neuroimaging. Curr Opin Neurobiol 2004;14:769-776.

37 Schultz W, Tremblay L, Hollerman JR: Reward processing in primate orbitofrontal cortex and basal ganglia. Cereb Cortex 2000; 10:272-284

38 Keedwell P, Drapier D, Surguladze S, Giampietro V, Brammer M, Phillips M: Neural markers of symptomatic improvement during antidepressant therapy in severe depression: subgenual cingulate and visual cortical responses to sad, but not happy, facial stimuli are correlated with changes in symptom score. J Psychopharmacol 2009;23:775-788.

39 Lee BT, Seong Whi C, Hyung Soo K, Lee BC, Choi IG, Lyoo IK, Ham BJ: The neural substrates of affective processing toward positive and negative affective pictures in patients with major depressive disorder. Prog Neuropsychopharmacol Biol Psychiatry 2007;31:1487-1492.

40 Fletcher PC, Frith CD, Baker SC, Shallice T, Frackowiak RS, Dolan RJ: The mind's eye precuneus activation in memory-related imagery. Neuroimage 1995;2:195-200.

41 Aharon I, Etcoff N, Ariely D, Chabris CF, O'Connor E, Breiter HC: Beautiful faces have variable reward value: $\mathrm{fMRI}$ and behavioral evidence. Neuron 2001;32:537-551.

42 McFarland BR, Klein DN: Emotional reactivity in depression: diminished responsiveness to anticipated reward but not to anticipated punishment or to nonreward or avoidance. Depress Anxiety 2009;26:117-122.

43 Martin-Soelch C: Is depression associated with dysfunction of the central reward system? Biochem Soc Trans 2009;37:313-317.

44 Davey CG, Yucel M, Allen NB: The emergence of depression in adolescence: development of the prefrontal cortex and the representation of reward. Neurosci Biobehav Rev 2008;32:1-19. 